\title{
Quantitative assessment of morphological variation of six Pseudococcomyxa strains by geometric morphometric descriptors
}

\author{
Jiř́i Neustupa* \& Katarína Nemjová \\ Department of Botany, Faculty of Science, Charles University of Prague, Benátská 2, CZ-128 01 Prague, Czech \\ Republic, *corresponding author, e-mail: neustupa@natur.cuni.cz
}

\begin{abstract}
We conducted a geometric morphometric analysis of the cellular shape in six Pseudococcomyxa strains that were isolated from different microhabitats (bark, needles, bare wood) and from different regions. The analysis was based on 14 landmarks, with 12 of them allowed to slide along their abscissae. The size differences did not correlate with ecological characteristics, but the shape descriptors analysis resulted in three distinguished groups: a pair of tropical strains, three strains isolated from spruce needles and a single strain from the fir bare wood. We propose that quantitative shape features of Coccomyxa-like algae could be used for their future phenotypic characterization.
\end{abstract}

Key words: Pseudococcomyxa, geometric morphometrics, thin-plate spline, Trebouxiophyceae

\section{Introduction}

Morphological assessment of aero-terrestrial coccoid green algae has always been hampered by their simple cell shapes, ranging mostly from irregularly elliptical to globular, and providing few reliable features available for characterization of individual strains or taxa. The genera Coccomyxa Schmidle and Pseudococcomyxa Korsh, which belong to the most frequent algae in bark samples throughout the world, but frequently occur also in soils and in other aero-terrestrial environments (ETTL \& GÄRTNER 1995), represent typical examples of this morphological puzzle. These genera have been distinguished by their differences in mucilage production. The genus Pseudococcomyxa differs from Coccomyxa members by producing a mucilaginous cap on the apical part of the cells instead of mucilaginous sheet covering the cell surface as a whole (KoMÁreK \& FotT 1983). The members of both genera have elongated, irregularly elliptical vegetative cells and they reproduce entirely by means of asexual autospores (KoMÁREK \& FotT 1983, HindÁK 1984). The recent molecular data indicate that members of these two genera form a single trebouxiophycean clade containing a lot of species that, however, cannot be differentiated into genera according to the traditional mucilage-production criterion (FRIEDL et al. 2007). There were about 40 taxa described within the genus Coccomyxa during the 20th century on the basis of morphological features such as cell dimensions, number of autospores or qualitative assessment of cellular shape, but only six of these were considered suitable for identification of natural populations by ETTL \& GÄRTNER (1995). In total, three species have been described in the genus Pseudococcomyxa, but the widely defined type species $P$. simplex (MAINX) Fотт has been reported in the vast majority of floristic and diversity papers. Similarly to most other trebouxiophycean lineages, the molecular data indicate higher species diversity than was estimated using traditional morphological approaches (FRIEDL et al. 2007). However, their characterization by traditional expert-based judgement of morphology is probably nearly impossible for the lack of reliable discriminating qualitative features between individual strains.

On the other hand, the independent phenotypic evidence is certainly very important for eventual taxonomic conclusions resulting from molecular data. In this respect, we believe that recent morphometric methods can provide a promising way to deal with variable and featureless shapes of Coccomyxa and Pseudococcomyxa algae. The landmark-based geometric morphometrics, which resulted from "the morphometric revolution" of the 1990s (Rohlf \& Marcus 1993, Adams et al. 2004), is 
currently considered probably the most powerful way of investigating variation of biological shapes (SLICE 2007). It is based on the so called Procrustes superimposition of corresponding landmarks depicted on an investigated structure. Procrustes superimposition involves removing the effects of position, rotation and size so that the resulting residual differences in coordinates of individual landmarks represent the actual shape differences between investigated objects. One of the major assets of geometric morphometrics is that it allows to model the shape changes within morphospace determined by shape characteristics of investigated set of objects including the principal trends of morphological variation or shapes characteristic of individual sub-groups representing e.g. taxa or populations within a larger data set (ZELDITCH et al. 2004). In phycology, geometric morphometrics has recently gained an increasing popularity in diatom, chrysophyte (e.g. Neustupa \& NĚmCOvÁ 2007, Potapova \& Hamilton 2007) and green algal research (e.g. VerbrugGen et al. 2005, Neustupa \& ŠKaloud 2007), but Coccomyxa-like green algae have never been investigated using these methods.

In this study, we chose six aero-terrestrial Pseudococcomyxa strains that correspond to the widely defined type species $P$. simplex by traditional morphological data. We conducted the geometric morphometric analysis of the twodimensional projections of cells arranged along their longitudinal axes. We primarily asked the two following questions:

a) Can geometric morphometrics distinguish individual strains of Coccomyxa-like algae?

b) Is there any correlation between microhabitat type or locality of strain originand its morphometric characteristics (shape, size)?

\section{Material and methods}

The six investigated strains were isolated from the following localities:

a) the Ps-1 strain - the bark sample of Ehretia javanica BLUME, mountainous rainforest, Cibodas, West Java, altitude 1500 m.a.s.1.;

b) the Ps-2 strain - the bark sample of Cleistocalyx operculata (RoxB.) MERr. \& PERry, mountainous rainforest, Cibodas, West Java, altitude 1500 m.a.s.1.;

c) the Ps-3 strain - the algal growth on needles of
Picea abies, Kokořín Castle, The Kokořínsko Protected Landscape Area, The Czech Republic, altitude 350 m.a.s.1;

d) the Ps-4 strain - the algal growth on bare wood of Abies alba, The Hoverla Carpathian Biosphere Reserve, Ukraine, altitude 1000 m.a.s.1.;

e) the Ps-5 strain - the algal growth on needles of Picea abies, Želízy, The Kokořínsko Protected Landscape Area, The Czech Republic, altitude 220 m.a.s.l.;

f) the Ps-6 strain - the algal growth on needles of Picea abies, Želízy, The Kokořínsko Protected Landscape Area, The Czech Republic, altitude 220 m.a.s.1.

All the strains were cultivated on BBM agar-solidified medium (Bischoff \& Bold 1963) at temperature $20^{\circ} \mathrm{C}$ and by daylight illumination. Microphotographs were taken by Olympus BX51 light microscope and Olympus Z5060 digital equipment using Nomarski differential contrast after 8 weeks of cultivation. We randomly selected 30 cells in each strain and digitised 14 landmarks along their outlines (Fig. 1). Two landmarks were delimited on the apical and basal extremities of the cells. In addition, six landmarks were delimited along both the ventral and dorsal sides. These 12 landmarks were the so called semilandmarks allowed to slide along their abscissae (BoOKSTEIN 1997, ZELDITCH et al. 2004).

Most of the morphometric analyses were conducted using TPS software package for geometric morphometrics (RoHLF 2006) and statistical analyses were done in PAST Ver. 1.75 (HAMmer et al. 2001). The individual cells were superimposed using the generalised Procrustes analysis. The size of the cells was evaluated using centroid size measure (square root of the sum of squared distances from the landmarks to their centroid), which is a standard size measure in morphometric studies. As the landmarks were regularly distributed along the outline of a cell, centroid size

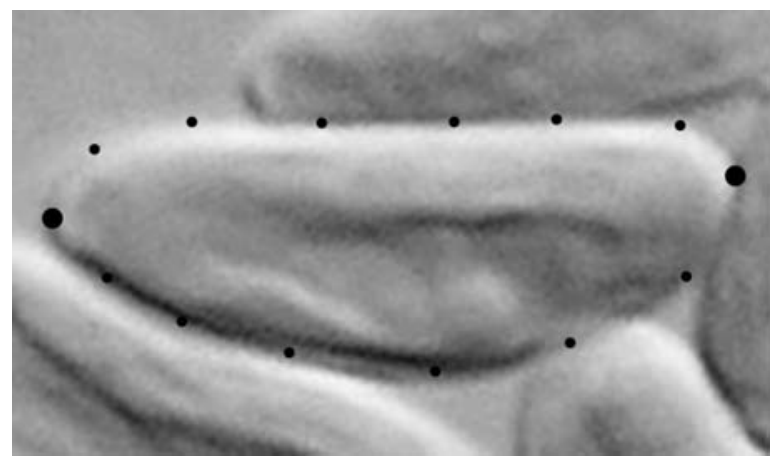

Fig. 1. The Pseudococcomyxa vegetative cell with 14 landmarks for morphometric analysis. The two large circles indicate fixed landmarks, the 12 small landmarks indicate the semilandmarks. 

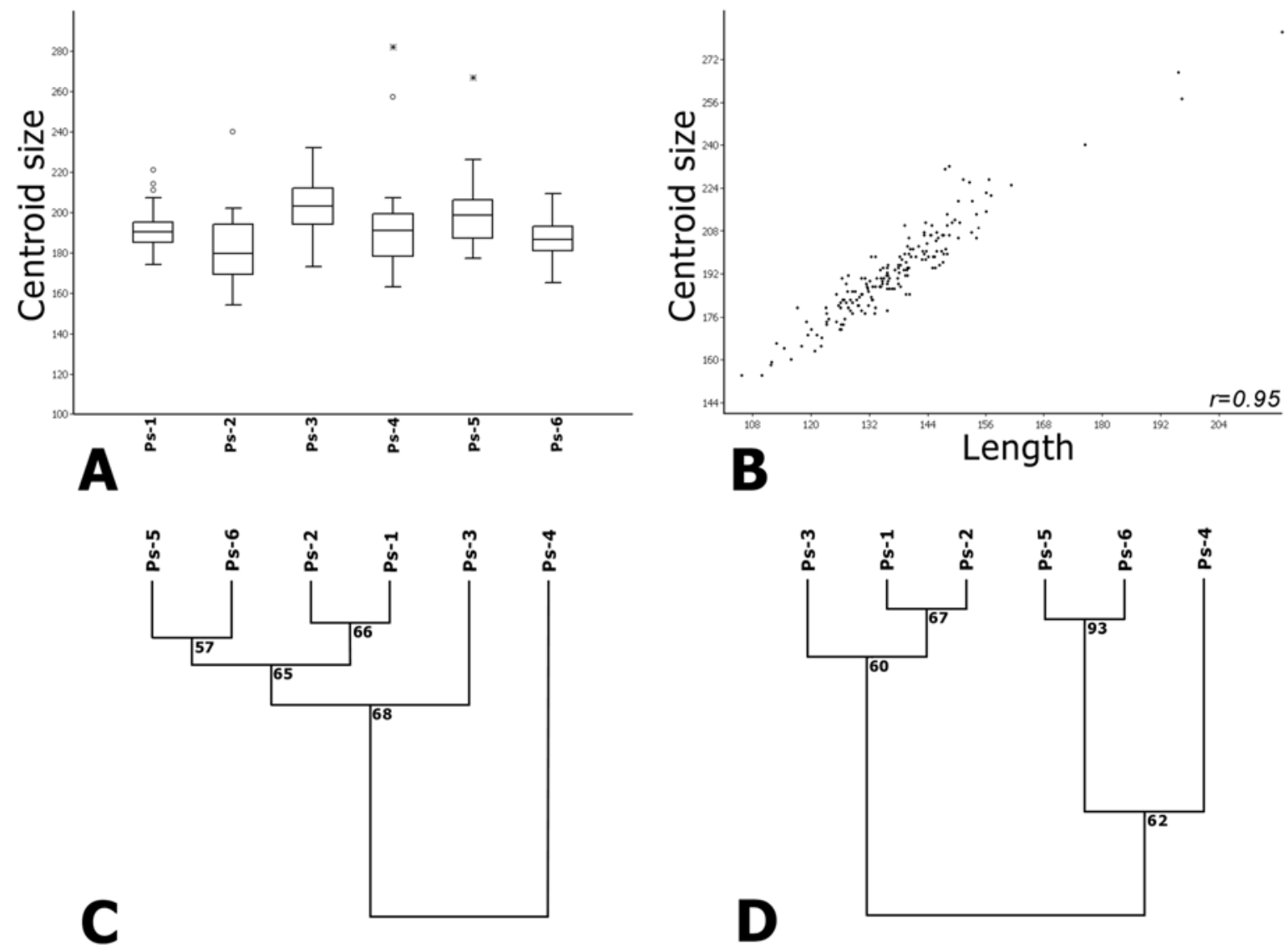

Fig. 2. The results of size and shape analyses. A: The box-plot of centroid size of the investigated strains; B: Relation between centroid size and length of the cells; C: The UPGMA dendrogram of shape data. Bootstrap numbers are based on 10000 repetitions; D: The Ward`s method dendrogram of shape data. Bootstrap numbers are based on 10000 repetitions.

Table 1. The results of statistical tests on differentiation between investigated strains. CS: the permutation $t$-tests on centroid size difference, VAR: the F-tests on difference in variance, shape: the two-group multivariate permutation tests on difference in cellular shape. ${ }^{* * *}: p$ value $<0.001, * *: p$ value between 0.001 and $0.01, *: p$ value between 0.01 and $0.05,-:$ not significant.

\begin{tabular}{|c|c|c|c|c|c|}
\hline & Ps-2 & Ps-3 & Ps-4 & Ps-5 & Ps-6 \\
\hline Ps-1 & $\begin{array}{l}\text { CS ** } \\
\text { VAR * } \\
\text { shape - }\end{array}$ & $\begin{array}{l}\text { CS ** } \\
\text { VAR - } \\
\text { shape * }\end{array}$ & $\begin{array}{l}\text { CS - } \\
\text { VAR *** } \\
\text { shape *** }\end{array}$ & $\begin{array}{l}\text { CS - } \\
\text { VAR * } \\
\text { shape - }\end{array}$ & $\begin{array}{l}\text { CS * } \\
\text { VAR - } \\
\text { shape * }\end{array}$ \\
\hline Ps-2 & & $\begin{array}{l}\text { CS } * * * \\
\text { VAR - } \\
\text { shape ** }\end{array}$ & $\begin{array}{l}\text { CS * } \\
\text { VAR - } \\
\text { shape *** }\end{array}$ & $\begin{array}{l}\text { CS *** } \\
\text { VAR - } \\
\text { shape - }\end{array}$ & $\begin{array}{l}\text { CS - } \\
\text { VAR *** } \\
\text { shape - }\end{array}$ \\
\hline Ps-3 & & & $\begin{array}{l}\text { CS * } \\
\text { VAR * } \\
\text { shape *** }\end{array}$ & $\begin{array}{l}\text { CS - } \\
\text { VAR - } \\
\text { shape * }\end{array}$ & $\begin{array}{l}\text { CS } * * * \\
\text { VAR ** } \\
\text { shape *** }\end{array}$ \\
\hline Ps-4 & & & & $\begin{array}{l}\text { CS - } \\
\text { VAR - } \\
\text { shape *** }\end{array}$ & $\begin{array}{l}\text { CS - } \\
\text { VAR *** } \\
\text { shape *** }\end{array}$ \\
\hline Ps-5 & & & & & $\begin{array}{l}\text { CS *** } \\
\text { VAR *** } \\
\text { shape - }\end{array}$ \\
\hline
\end{tabular}


corresponds to the area of two-dimensional projection of an analysed cell. In addition, we measured the length of all the analysed cells and related it to centroid size in order to assess their correlation. The differences in size between pairs of individual strains were evaluated using permutation $t$-tests (10 000 permutations). F-tests were used to assess differences in variance of size between pairs of strains.

We performed the principal component analysis (PCA) of the geometric morphometric data and used the first ten PC axes for the subsequent statistical analyses. The canonical variates analysis (CVA) was used to test for and to illustrate the differences in shape between individual strains. The shape differences between all the group pairs were evaluated using the two-group permutation tests on Mahalanobis distance with 1000 permutations. In addition, the relation between morphometric shape characteristics of individual strains was illustrated by cluster analysis using UPGMA with the Euclidean distance as distance measure and Ward's methods. The bootstrap numbers of individual nodes were assessed using 10000 repetitions. The shape characteristics of individual groups were illustrated as thin-plate splines of the mean group configurations from the overall consensus.

\section{Results}

All the investigated strains had typical Pseudococcomyxa simplex morphology with the elongated irregular cells, where apical and basal poles as well as the ventral and dorsal sides could be discerned (Fig. 1). Dimensions of the cells were (4-)4.5-11.0-(13.0) × (1.8-)2.5-4.0(-6.5) $\mu \mathrm{m}$. The length of the cells was tightly related to centroid size $(\mathrm{r}=0.95, p=0.001)$ (Fig. 2B) and further analyses were conducted using centroid size as the unitary size measure of cells. The $P S-3$ strain had the largest cells on average and this difference was significant in comparison with all the other strains, with the single exception of the $P s-5$ strain (Fig. 2A, Table 1). On the other hand, the $P S-2$ strain clearly had the smallest cells and they were significantly different in size from all the other strains, with the exception of the Ps-6 strain (Fig. 2A, Table 1). There was no clear relation between size and its variance and the locality and microhabitat type. The pair of tropical strains ( $P s-1$ and $P s-2)$ differed significantly both in size and in their variance. Similarly, the pair of the strains isolated from spruce needles in Želízy, The Czech Republic, highly significantly differed in both these measures.

When looking at the shape characteristics,

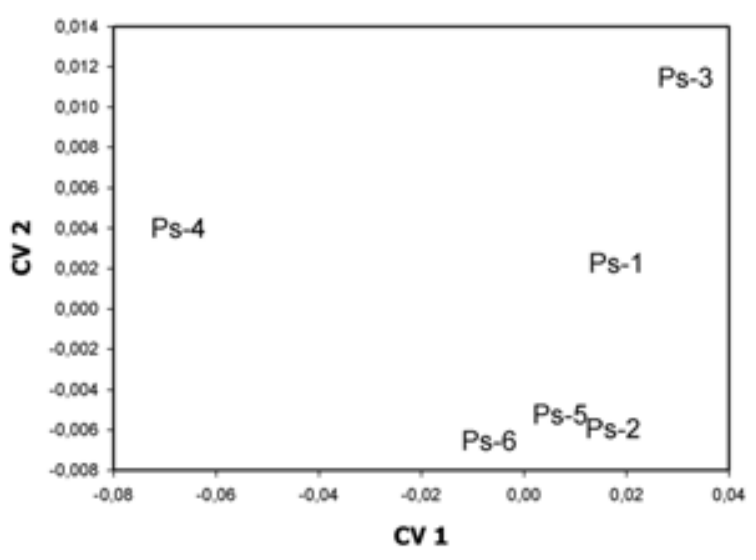

Fig. 3. The canonical variates ordination plot of the first two axes indicating centroid position of individual strains.

we encountered a considerably different situation. The first PC axes spanned $99.2 \%$ of the total variation in the data and the CVA of these morphometric descriptors revealed highly significant shape differentiation among the strains (Wilk's $\lambda=0.34, \mathrm{~F}=4.05, p<0.0001$ ). The pair of the first two CV axes spanned most of the variation that discriminated the groups (CV1: 74.3\%, CV2: 17.9\%). Their diagram illustrated that the $P s-4$ strain from Ukrainian Abies alba bare wood differed most profoundly from all the other strains (Fig. 3). This difference was unambiguously confirmed also by pair tests on shape descriptors (Table 1). In this case, the $P s-3$ strain differed from the rest of other strains that formed a more closely similar group. The dendrograms illustrated similarity in shape between the tropical strains $(P S-1$ and $P s-2)$ and the pair of strains isolated from Picea abies needles in Želízy, The Czech Republic ( $P_{S-5}$ and $P s-6$ ) (Figs 2C, D). The Ukrainian bare wood $P s-4$ strain was consistently the least similar to all the other investigated strains. The thin-plate splines of group consensual configurations from the overall consensus demonstrated that the Ps-4 strain had clearly the thinnest cells (Fig. 4). The tropical strains, however, were relatively thick and their basal pole was more rounded than in the other strains. The $P_{s-3}, P_{s-5}$ and $P_{s-}-6$ strains isolated from spruce needles in the Kokořinsko region of the Czech Republic had the least heteropolar shape with relatively obtuse apical and basal poles. 

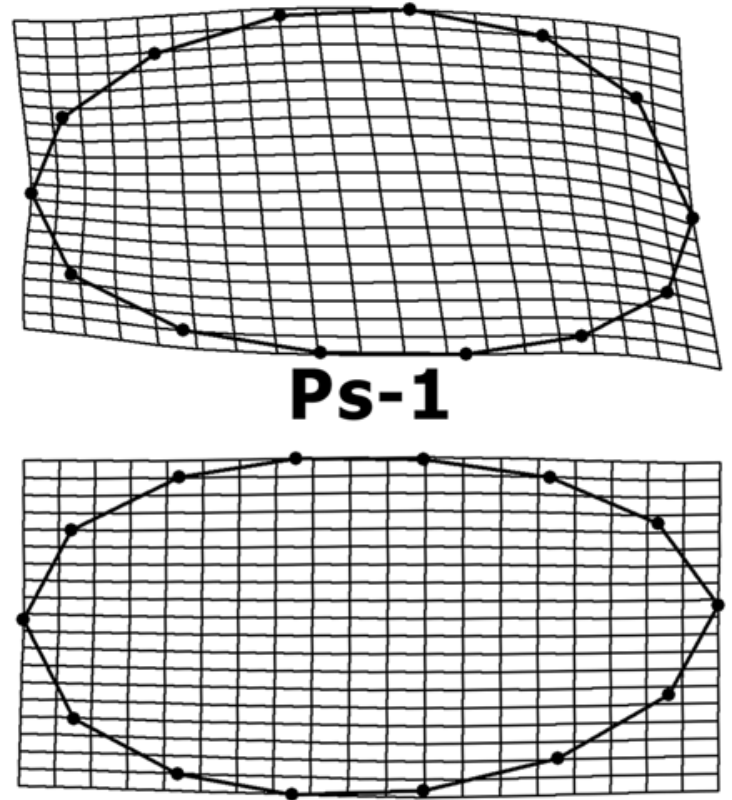

Ps-3

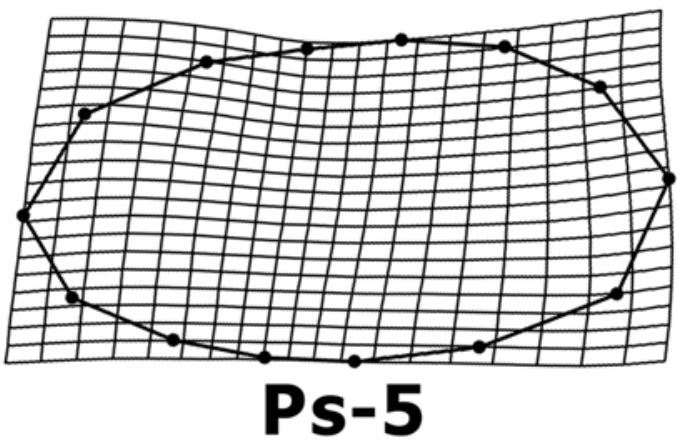

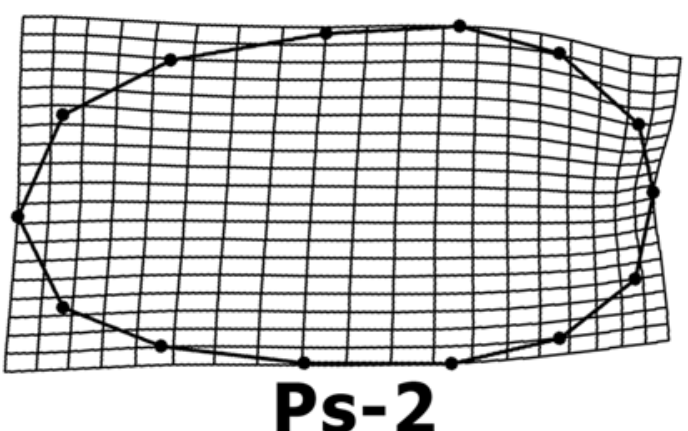

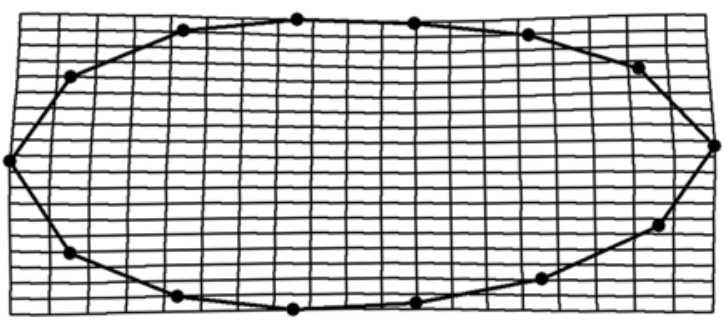

Ps-4

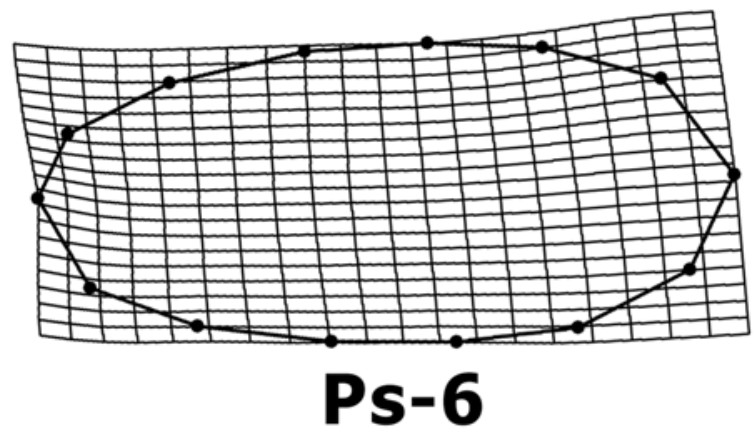

Fig. 4. The thin-plate splines indicating shapes characteristics of individual group centroids from the overall consensus. The splines were three-times magnified to enhance their visual differences.

\section{Discussion}

Taxonomy of Coccomyxa-like green algae is confusing (ETTL \& Gärtner 1995, KostiKov et al. 2002) and the revision will certainly be based on molecular data. However, here we have shown that quantitative approaches of geometric morphometrics can undoubtedly provide a useful comparative data set. We have discovered that shape, not size, discriminates among investigated Pseudococcomyxa strains from individual localities and microhabitats. Although the size varied between strains, it did not correlate with their ecology and morphology. In contrast, morphometric descriptors clustered together the pair of tropical strains (Figs. 2C, D) and the strains isolated from spruce needles in the Czech Republic (Fig. 2D). The single strain isolated from bare fir wood was consistently the most dissimilar from all the other strains. We should note that even those morphological differences between the pairs of strains that proved highly significant in statistical testing (Table 1) were so minute that they would probably be indiscernible "by eye" in traditional qualitative morphological evaluation. The discriminating morphological characteristics of individual strains depicted in Figure 4 were three times magnified in order to make them clearly visible.

We believe that geometric morphometric analysis of cellular outlines of unicellular green algae provides useful information on their morphological differentiation. Similarly as in Coccomyxa-like algae, this type of morphometric assessment can be conducted in several other algal lineages with variable cellular outlines such as the trebouxiophycean genera Choricystis, Koliella, Nannochloris, chlorophycean genera Chlorolobion or Scenedesmus or in some 
unicellular eustigmatophycean algae (e.g. Monodopsis, Pseudocharaciopsis). In these organisms, geometric morphometrics can certainly become a standard method of phenotypic assessment of strains in the future.

\section{Acknowledgement}

The study has been supported by the grants of Czech Science Foundation no. 206/05/P139 and no. 206/06/0998.

\section{References}

Adams, D. C., Rohlf, F. J. \& Slice, D. E. (2004): Geometric morphometrics: ten years of progress following the ,revolution'. - Ital. J. Zool. 71: 5-16.

BooksteIn, F. L. (1997): Landmark methods for forms without landmarks: morphometrics of group differences in outline shape. - Med. Image Anal. 1: 225-243.

EtTL, H. \& GÄrTnER G. (1995): Syllabus der Boden-, Luftund Flechtenalgen. - 721 pp., Gustav Fischer Verlag, Stuttgart.

Friedl, T., Kostikov, I., Müller, J., Beck, A., Zufall-Roth, E. \& Hoffmann, L. (2007): A re-investigation of Pseudococcomyxa(Chlorophyta,Trebouxiophyceae): morphology, rDNA sequencing and AFLP fingerprinting to define species. - Proc. Abstr. Int. Conf. Taxonomy and Biology of Green Algae V., Smolenice.

Hammer, Ø., Harper, D. A. T. \& Ryan, P. D. (2001): PAST: Paleontological Statistics Software Package for Education and Data Analysis. - Palaeont. Electr. 4: $1-9$.

HindÁK, F. (1984): Studies on the chlorococcal algae (Chlorophyceae). III. - 308 pp., Veda, Bratislava.

KomÁReK, J. \& Fott, B. (1983): Chlorococcales. Das
Phytoplankton des Süßwassers, Bd. 7. - 1043 pp., Schweizerbart, Stuttgart.

Kostikov, I., Darienko, T., Lukešová, A. \& Hoffmann, L. (2002): Revision of the classification system of Radiococcaceae Fott ex Komárek (except the subfamily Dictyochlorelloideae) (Chlorophyta). Algological Studies 104: 23-58.

Neustupa, J.\& NĚMCOVÁ, Y.(2007):Ageometric morphometric study of the variation in scales of Mallomonas striata (Synurophyceae, Heterokontophyta). - Phycologia 46:123-130.

Neustupa, J. \& ŠKaloud, P. (2007): Geometric morphometrics and qualitative patterns in the morphological variation of five species of Micrasterias (Zygnemophyceae, Viridiplantae). - Preslia 79: 401-417.

Potapova, M. \& Hamilton, P. B. (2007): Morphological and ecological variation within the Achnanthidium minutissimum (Bacillariophyceae) species complex. - J. Phycol. 43: 561-575.

Rohlf, F. J. (2006): TPS Series - Dep. Ecol. Evol., State Univ. New York at Stony Brook, New York.

Rohlf, F. J. \& Marcus, L. F. (1993): A revolution in morphometrics. - Trends Ecol. Evol. 8: 129-132.

Slice, D. E. (2007): Geometric morphometrics. - Ann. Rev. Anthropol. 36: 261-281.

Verbruggen, H., De Clerck, O., Cocquyt, E., Kooistra, W. H. C. F. \& Coppejans, E. (2005): Morphometric taxonomy of siphonous green algae: Amethodological study within the genus Halimeda (Bryopsidales). - J. Phycol. 41: 126-139.

Zelditch M. L., Swiderski D. L., Sheets D. H. \& Fink W. L. (2004): Geometric morphometrics for biologists: a primer. - 452 pp., Elsevier Academic Press, London.

(C) Czech Phycological Society

Received January 15, 2008

Accepted April 1, 2008 